\title{
Liquid Chromatographic Determination of Scopolamine in Hair with Suspended Drop Liquid Phase Microextraction Technique
}

\author{
Mahboubeh Masrournia ${ }^{1^{*}}$, Zarrin Es'haghi $^{2}$, Mostafa Amini ${ }^{1}$ \\ ${ }^{1}$ Department of Chemistry, Faculty of Sciences, Mashhad Branch, Islamic Azad University, Mashhad, Iran \\ ${ }^{2}$ Department of Chemistry, Faculty of Sciences, Payam Noor University, Tehran, Iran \\ E-mail: masrournia@yahoo.com, masrour@mshdiau.ac.ir \\ Received December 3, 2010; revised March 10, 2011; accepted March 14, 2011
}

\begin{abstract}
Hair analysis is used in some branches of alternative medicine as a method of investigation to assist diagnosis. It is very useful when a history of drug use is difficult or impossible to obtain. In this research suspended droplet liquid phase microextraction (SDLME) coupled with high-performance liquid chromatography and photodiode array detection (HPLC-DAD) was used for preconcentration and analysis of scopolamine in hair samples. Therefore scopolamine was extracted from $2.0 \mathrm{~g}$ hair sample incubated in methanol $\left(5 \mathrm{~h}, 50^{\circ} \mathrm{C}\right)$ and adjusted to $\mathrm{pH} 7.4$ with, $\mathrm{Na}_{2} \mathrm{HPO}_{4}-\mathrm{H}_{3} \mathrm{PO}_{4}$ buffer solution (donor phase, $\left.\mathrm{P}_{1}\right)$ into an organic phase $\left(\mathrm{P}_{2}\right) 350 \mu \mathrm{n}$-octanol and then back extracted into a micro drop of aqueous acceptor phase $\left(\mathrm{P}_{3}\right)$, adjusted at $\mathrm{pH} 3$, with HCL. The extraction time, $\mathrm{T}_{1}$ (from $\mathrm{P}_{1}$ to $\mathrm{P}_{2}$ ) was 2 min and $\mathrm{T}_{2}$ (from $\mathrm{P}_{2}$ to $\mathrm{P}_{3}$ ) was 30 min. Optimum instrumental conditions were included; $\mathrm{A}_{18}$ reverse phase column with water-acetonitrilemethanol (80:10:10) as the mobile phase was used and wavelength for UV detection was $205 \mathrm{~nm}$. The linear range was 10 to $10000 \mathrm{ng} \cdot \mathrm{mL}^{-1}$, enrichment factor, detection limit and relative standard deviation were 77 , $0.1 \mathrm{ng} \cdot \mathrm{mL}^{-1}$ and 5.4 respectively.
\end{abstract}

Keywords: Column Liquid Chromatography, Directly Suspended Droplet Liquid Phase Microextraction (SDLME), Scopolamine, Hair Sample

\section{Introduction}

Tropane alkaloids such as atropine and scopolamine (Figure 1) are muscarinic antagonists that block neuron-transmission across muscarinic cholinergic receptors. The toxicity of these drugs has been well known for centuries and has been linked to poisoning and death, usually due to heart or respiratory failure. Scopolamine was shown toxic effects on central and peripheral nervous system [2]. Besides an increase of recreational abuse [3], scopolamine has been occasionally used for its sedative properties.

Tropane alkaloid determination in biological samples such as serum, blood, urine and hair has a significant importance in poisoning and forensic case [4]. Moreover hair analysis is a new perspective in forensic toxicology $[5,6]$.

Hair may be considered for retrospective purposes when blood and urine are no longer expected to contain a particular contaminant, typically a year or less. Its most widely accepted use is in the fields of forensic toxicology and environmental toxicology. Several alternative medicine fields also use various hair analysis for environmental toxicology but these uses are controversial and not standardized [7] But, drug determination in the human

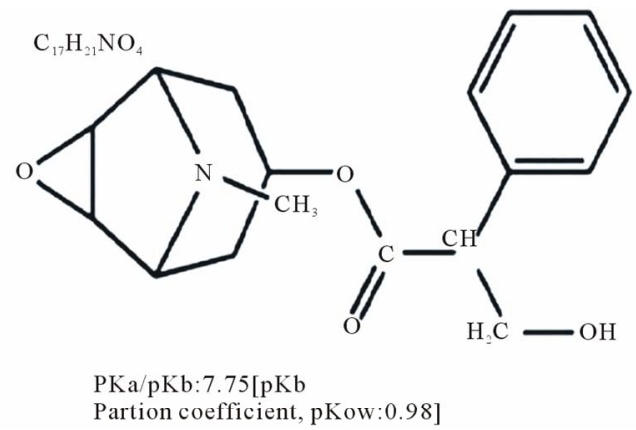

Figure 1. Structure of the scopolamine and its pKa and log Po/w values [1]. 
hair or biological fluids is often complicated by low analyte concentration and the complex sample matrix. Because of this, sample preparation is crucial in drug analysis and includes both analyte pre-concentration and sample clean-up [8].

Some methods for analyzing tropane alkaloids in biological samples have been published including HPLCMS-MS [4] and LC-MS-MS [5,9]. These methods require laborious sample preparation and expensive instruments.

Relatively recent three phase microextraction was developed to extract ionisable and chargeable compounds from different aqueous samples [10,11]. Ma and Cantwell used an organic solvent to separate two aqueous phase, donor phase and acceptor phase. The $\mathrm{pH}$ of donor phase was adjusted to basic and the acceptor phase was acidic (for basic compounds). An ionisable compound was extracted from the donor phase into the organic phase, and then back extracted into the acceptor phase. Compared to the supported liquid membrane (SLM), suspended droplet liquid phase microextraction (SDLME) uses an unsupported liquid organic membrane. The thickness of the organic film is easier to control, and because this organic layer is changed for every extraction, no memory effect was observed together with long term instability in SDLME [12].

In the present work, a simple SDLME device was set-up to pre-concentrate scopolamine from hair samples before HPLC analysis. We also investigated various aspects of the microextraction conditions including the effect of organic solvent, composition of acceptor and donor phase, extraction times in each step, and stirring rates. The main aim of our work is to develop a preconcentration SDLME technique for scopolamine extraction to make its evaluation in hair samples with HPLC method feasible.

\section{Experimental}

\subsection{Chemicals and Reagents}

Scopolamine was purchased from Sigma-Aldrich (Saint Louis, USA). HPLC grade water, methanol and acetonetrile also were purchased from Merck (Darmstadt, Germany) and 1-octhanol from Applichem (Darmstadt, Germany). Main stock solution of the scopolamine (2000 $\mu \mathrm{g} \cdot \mathrm{L}^{-1}$ ) was prepared in methanol and stored at $4^{\circ} \mathrm{C}$. Fresh sample solutions containing scopolamine at different concentrations were prepared from the main stock solution.

\section{Hair Samples and Working Solutions}

A bulk of blank hair, necessary for method development and validation, was obtained from a men hairdresser's shop. The absence of scopolamine was verified. Hair samples were obtained from addiction therapeutic center of Azadshahr, Mashhad, Iran.

A standard of hair about $5 \mathrm{~mm}$ in diameter was cut from close to the scalp at the vertex posterior area. Samples 2 - $4 \mathrm{~cm}$ long were selected for analysis.

2.0 grams of the hair samples were washed with different solvents as follow: $20 \mathrm{~mL}$ dichloromethane, 15 $\mathrm{mL}$ acetone, $15 \mathrm{~mL}$ methanol, $10 \mathrm{~mL}$ methanol, at room temperature for $5 \mathrm{~min}$ and then it was dried. The washed and dried hair was finally cut into approximately $1 \mathrm{~mm}$ pieces and digested by the following procedure: $2 \mathrm{ml}$ methanol as an extracting solvent was added to $40 \mathrm{mg}$ of hair. The $\mathrm{pH}$ was adjusted to 7.4 by phosphate buffer solution. The samples were incubated at $50^{\circ} \mathrm{C}$ for $5 \mathrm{~h}$ [13]. In case of a remaining solid matrix, extracts were filtered. The remaining was rinsed with $1 \mathrm{~mL}$ ethanol and it was added to the extracted solution.

Stock solution containing $2.0 \mathrm{mg} \cdot \mathrm{mL}^{-1}$ of scopolamine was prepared, in methanol and stored at $4^{\circ} \mathrm{C}$. Standard solutions were obtained by adding calculated amounts of the stock solution into the blank hair solutions which were prepared .These working samples were used for optimization experimental and calibration curve. Limit of detection (LOD) and limit of quantification (LOQ) of the analyte were determined by decreasing concentrations of spiked samples until signal to noise ratio $(\mathrm{S} / \mathrm{N})$ of 3 and 10 were obtained, respectively. All solutions were stored at $4^{\circ} \mathrm{C}$ and protected from light.

\subsection{Instrumentation}

\subsubsection{HPLC System}

The HPLC system used in this work was a Knauer (d14163, Germany) and consisted of a photodiode Knauer (S2600) tunable absorbance detector and a 100/5-RP-18 column (4.6 mm diameter, $250 \mathrm{~mm}$ length) from Knauer (Germany), was used for separation. A RP-18 guard column was fitted upstream of the analytical column. The mobile phase was water- methanol-acetonitrile optimized on $(80: 10: 10 \mathrm{~V} / \mathrm{V})$ and delivered by two Knauer S-1000 HPLC pumps. The flow rate of the mobile phase was: $1 \mathrm{~mL} \cdot \mathrm{min}^{-1}$ and the UV detection wavelength were monitored at $205 \mathrm{~nm}$.

\subsubsection{Suspended Droplet Liquid Phase Microextraction (SDLME Procedure)}

The microextraction device is shown in Figure 2. The sample solution $5 \mathrm{ml}$ adjusted to $\mathrm{pH} 10$ with $\mathrm{NaOH} 0.1$ $\mathrm{M})$ was placed in a $6 \mathrm{~mL}$ vial. Then $350 \mathrm{ml}$ organic solvent was added and a stirring bar was $(2 \mathrm{~mm} \times 7 \mathrm{~mm})$ placed in the solution. An aluminum foil was used to cover the lid of the vial during extraction to prevent the 


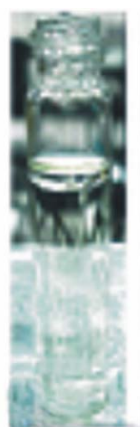

(a)

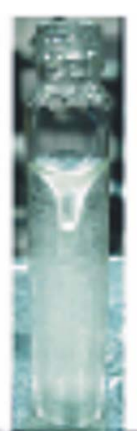

(b)

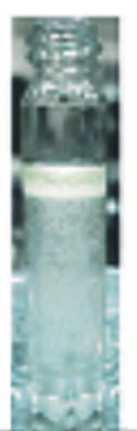

(c)

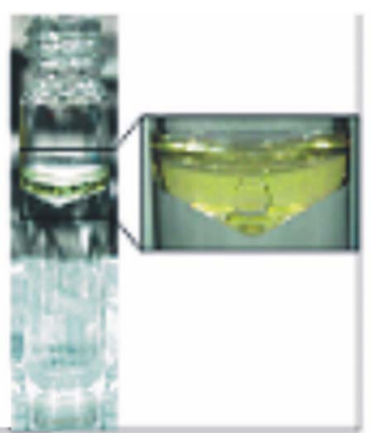

(d)
Figure 2. Illustration of the microextraction procedure for directly suspended droplet. SDLME: (a) addition of the organic solvent to the aqueous sample solution, magnetic stirrer is off; (b) the mixture is being agitated, extraction procedure; (c) separation of the tiny drop of the organic solvent and aqueous sample solution and then addition of the acceptor phase in to the organic solvent, magnetic stirrer is off; (d) back-extraction procedure, magnetic stirrer is on [18].

evaporation of the organic phase. Then the mixture was put on a Yellow line (USA) heater and magnetic stirrer and was agitated for $5 \mathrm{~min}$ at $500 \mathrm{rpm}$. In the later step a $100 \mu \mathrm{L}$ flat-cut HPLC microsyringe (Knauer, Germany) was used to introduce the acceptor phase $(10 \mu \mathrm{L}$ droplet of de-ionized water adjusted to $\mathrm{pH} 5$ with $\mathrm{HCl} 0.1 \mathrm{M}$ ) to the top center position of the immiscible organic solvent. The mixture was stirred at $600 \mathrm{rpm}$ for $20 \mathrm{~min}$ to cause back-extraction. After this period the microdroplet was picked up by the same HPLC microsyringe and was injected into the HPLC system.

\section{Results and Discussion}

\subsection{Theory of SDLME}

SDLME consists of two processes and three phases: extraction from donor phase $\left(\mathrm{P}_{1}\right)$ into an organic solvent $\left(\mathrm{P}_{2}\right)$, and finally back-extraction from the organic phase into an aqueous acceptor phase $\left(\mathrm{P}_{3}\right)$. In such cases, the $\mathrm{pH}$ of the sample is adjusted to make the analyte neutral and thus extractable into the organic solvent. After reaching the equilibrium of phase separation, the analyte that are mostly transferred into the organic phase are back-extracted into the second aqueous phase (acceptor) set to a $\mathrm{pH}$ at which, the analyte are charged. This backextraction step introduces extra selectivity since neutral compounds will preferably stay in the organic phase [14, $15]$. The theory of the method is well defined by the others $[16,17]$.

\subsection{Optimization Procedure}

To obtain the optimal extraction conditions for the best efficiency, various parameters like organic solvent, extraction and back-extraction times, different volumes of phases, stirring speed, $\mathrm{pH}$, this can be discussed as follows:

\subsubsection{Organic Solvent Selection}

In SDLME, the type of the organic solvent is an essential factor for achieving the efficient analyte preconcentration. There are several requirements for obtaining the selected organic solvent. The organic phase serves to separate the aqueous acceptor phase from the aqueous donor phase. The organic phase must, therefore, be immiscible with both the acceptor and the donor phase. The solubility of the analyte should be higher in the organic phase than the donor phase to promote the extraction of the analyte. On the other hand, the solubility of the analyte should be lower in the organic phase compared to the acceptor phase, in order to achieve a high degree of recovery of analyte in the acceptor phase. The appropriate organic solvents in this work should have lower density than the water to float on the top of the aqueous sample solution. It should be immiscible with water to avoid dissolution in two aqueous phases, because it serves as a barrier between them. The organic solvent should have high viscosity to hold the microdroplet at its topcenter position (Figure 2) without using a microsyringe as supporting device.

During this experiment, several organic solvents were tested to investigate their effect on the extraction efficiency. Five organic solvents including 1-octanol, nHexane, dichloromethane, toluene and benzylalcohol, have been examined. Among 1-octanol, Toluen, $n$-Hexane, Benzylalcol, Dichlorometan, 1-octanol was selected, because of its higher viscosity, immiscible with aqueous solution and high extraction efficiency.

\subsubsection{Stirring Speed}

Agitation of the sample is routinely applied to accelerate the extraction kinetics. Increasing the stirring speed of the donor phase enhances extraction as the diffusion of analyte through the organic phase is facilitated and improves the repeatability of the extraction method $[18,19]$. Therefore, the stirring speed was also optimized for a better extraction. Different stirring rates (100 to $500 \mathrm{rpm}$ ) were checked (Figure 3) Sample agitation by using either vibration or magnetic stirring dramatically increased extraction, but the liquid drop (acceptor phase) at the end of the needle, to be lost under great agitation. Therefore the stirring speed was selected as $500 \mathrm{rpm}$.

\subsubsection{Extraction Time}

In the first step, analyte extracted from the aqueous sample into the organic solvent that is a slow equilibrium 


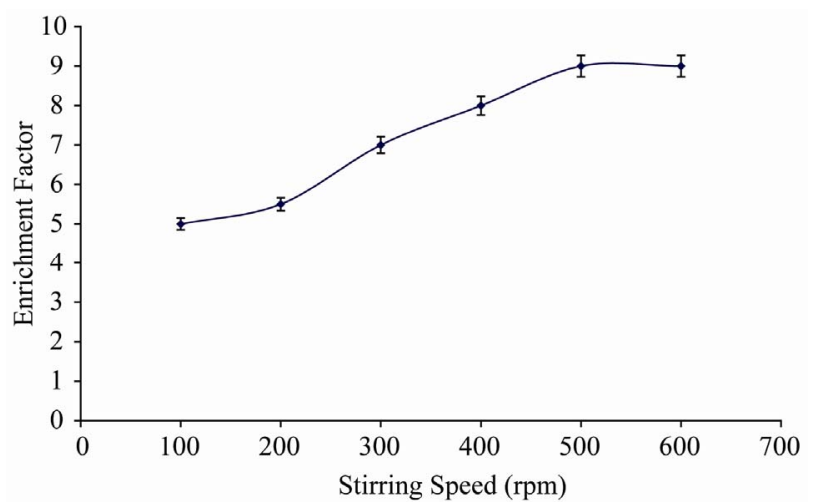

Figure 3. The effect of stirring speed on enrichment factor. Other extraction conditions: analyte concentration 5 $\mu \mathrm{g} \cdot \mathrm{mL}^{-1}$; 1-octanol as the organic solvent; sample $\mathrm{pH} \mathbf{1 0 . 0}$; acceptor phase $\mathrm{pH} \mathrm{3.0;} \mathrm{T}_{1}=2 \mathrm{~min}$, back-extraction time $\left(\mathrm{T}_{2}\right)$ $=30 \mathrm{~min} ; 5 \mathrm{~mL}$ donor sample volume; micro-droplet volume $10 \mu \mathrm{L}$.

process, and mass transfer is depended on time .With the passage of time solute molecules have sufficient time for transfer from donor phase to interface between the donor and organic phases and collection in organic phase. Therefore, extraction time is a significant factor in the extraction efficiency. The mixture of water sample and organic solution was agitated at 500rpm. Due to the high degree of mixing between the donor and organic phases the mass transfer is rapid. It has been reported that longer equilibration times do not have any significant effect on the extraction parameters [20,21] and in this work we observed that an equilibration time of $30.0 \mathrm{~min}\left(\mathrm{~T}_{1}\right)$ is sufficient to obtain a good extraction. SDLME is not an exhaustive extraction technique. Although maximum sensitivity is attained at the equilibrium, complete equilibrium needs not to be attained for accurate and precise analysis. Increasing this time causes increased extraction and leads to progressed enrichment factor. However, longer extraction time will result in the dissolution of extracted analyte in the organic phase and instability of the droplet especially under stirring. We have tested different back-extraction times the results are showed in Figure 4. On this basis, $30.0 \mathrm{~min}$ was selected as optimal back-extraction time for the experiment and after 30.0 min microdroplet is dissolved. The recovery percentage depends on the time that the analyte is in contact with the organic phase and the acceptor solution.

\subsection{4. $\mathrm{pH}$ of the Donor and Acceptor Phases}

In three-phase microextraction process, the $\mathrm{pH}$ of the donor phase is adjusted to produce molecular form of the analyte, and the acceptor phase is adjusted to ionize it. The difference in $\mathrm{pH}$ between the donor and acceptor phases can promote the extracted analyte from donor to acceptor phase [1,16,18,22-24].

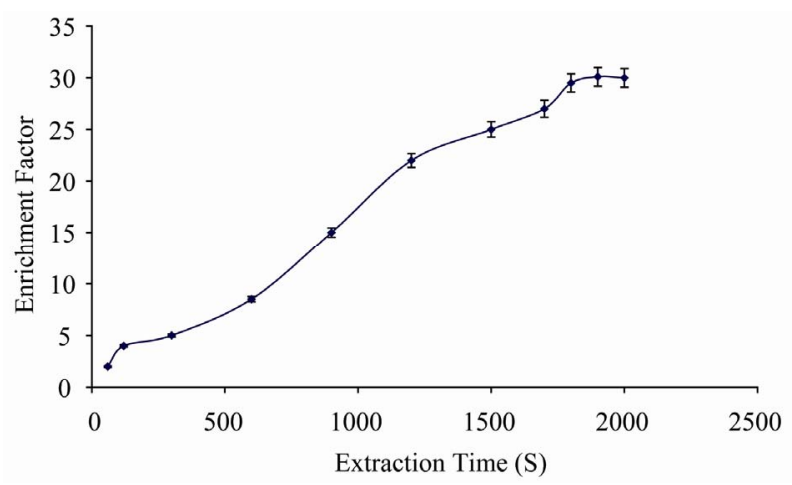

Figure 4. The effect of extraction time $\left(T_{2}\right)$ on enrichment factor. Other extraction conditions: analyte concentration 5 $\mu \mathrm{g} \cdot \mathrm{mL}^{-1}$; 1-octanol as the organic solvent; sample pH 10.0; acceptor phase pH 3.0; stirring speed $500 \mathrm{rpm}$; $5 \mathrm{~mL}$ donor sample volume; micro-droplet volume $10 \mu \mathrm{L}$.

Scopolamine is a moderately basic drug $\left(p K_{b}=7.75\right)$ and the $\mathrm{pH}$ of the aqueous sample should be higher than the $\mathrm{pKa}$ of the analyte, so that the analyte is neutral and extractable into the organic phase and contrary for acceptor phase. The effect of sample $\mathrm{pH}$ on the method efficiency in the range of $6-11$, and for acceptor solution in the range of 2.5 - 7 was evaluated. Although the peak area decreased with increasing acceptor $\mathrm{pH}$, the extraction efficiency was not affected significantly by $\mathrm{pH}$ in this range.

The maximum of enrichment factor was observed in donor phase $\mathrm{pH}=10$. The $\mathrm{pH}$ of acceptor phase decreased until the higher enrichment factor was obtained in $\mathrm{pH}=3$ (see Figure 5).

\subsubsection{Phase Volume}

Generally in the three-phase liquid microextraction sys-

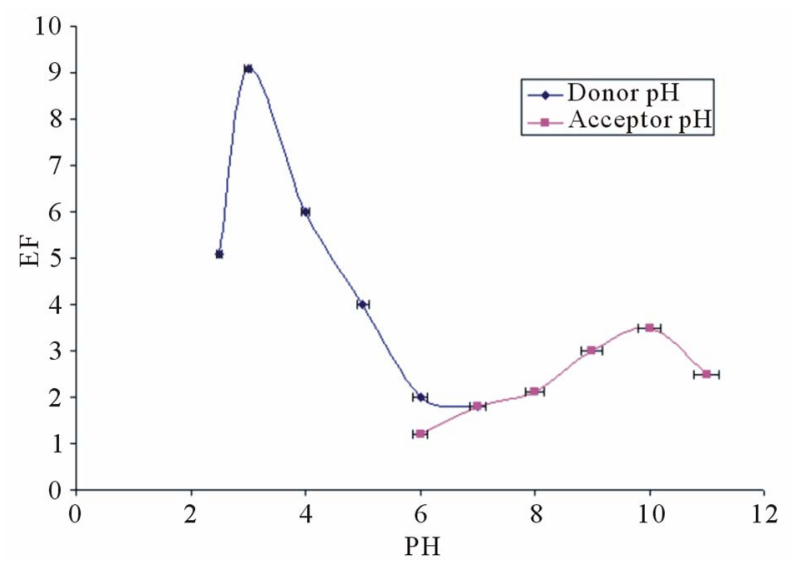

Figure 5. The effect of donor and acceptor phases $\mathrm{pH}$ on the extraction procedure. Extraction conditions: analyte concentration $5 \mu \mathrm{g} \cdot \mathrm{mL}^{-1} ; 350 \mu \mathrm{L}$ 1-octanol as organic solvent; $T_{1}=2$ min, back-extraction time $\left(T_{2}\right)=30$ min; stirring speed $500 \mathrm{rpm} ; 5 \mathrm{~mL}$ donor sample volume. 
tems, sensitivity of the method can be increased by decreasing the volume ratio of the acceptor to the donor phase $[22,23]$. However, the volume of the acceptor solution used for extraction may also be adjusted depending on the analytical technique coupled to liquid phase microextraction. For example, in contrast to GC, sample volumes in the range from 10 to $25 \mu \mathrm{L}$ are easily injected into a HPLC instrument, so the whole acceptor phase may be analyzed, potentially providing lower detection limits [24]. In this manner, the use of a large drop results in an increase of the analytical response. However, larger drops are difficult to manipulate [25]. Additionally, larger injection volumes result in band broadening [26]. Thus, in this investigation we used $5.0 \mathrm{~mL}$ donor phase $\left(\mathrm{P}_{1}\right), 350$ $\mu \mathrm{L}$ organic phase $\left(\mathrm{P}_{2}\right)$ and $10 \mu \mathrm{L}$ acceptor phase $\left(\mathrm{P}_{3}\right)$.

\subsection{Method Validation}

After optimization of all affective parameters, optimal conditions have been set to evaluate the performance of microextraction. In this research, experimental limits of detection were calculated as the minimum concentration providing chromatographic signals 3 times higher than background noise. In addition, the limit of quantification was calculated experimentally as the minimum concentration of scopolamine that provides chromatographic signals 10 times higher than background noise. We observed that LOD was $0.10 \mathrm{ng} \cdot \mathrm{mL}^{-1}$. The linearity of this method for analyte has been investigated over the ranges $10-10,000 \mathrm{ng} \cdot \mathrm{mL}^{-1}$ of scopolamine in the blank hair matrix. The obtained calibration equation was $\mathrm{y}=$ $0.0098 x+11.769\left(r^{2}=0.9978\right)$, where $y$ is the absorbance (in $\mathrm{mAU}$ ) and $\mathrm{C}$ the concentration of scopolamine in $\mathrm{ng} \cdot \mathrm{mL}^{-1}$ in the initial solution. The method showed good repeatability ( $\mathrm{RSD} \% 5.4, \mathrm{n}=5)$.

For calculation of enrichment factor, response of analysis after extraction by the investigated method should be divided to response of it before extraction. After that, enrichment factor was calculated by division of peak area results from injection of this solution, to peak area from initial sample. For reporting of this factor, we calculated enrichments of three standards solution (in the initial, mid and final reign of linear range) and the enrichment factor of the method was reported as the average of these calculates. We obtained enrichment factor 77.0. The review of some methods [27-33], which were used for determination of scopolamine in the environmental and biological samples is demonstrated in Table 1. As compare the other method low detection limits and high enrichment factors are readily achieved in present work.

\subsection{Real Sample Analysis}

To show the applicability of the method, we have analyzed the two sample hair. Figure 6 shows human hair prior (left) and after spiking with scopolamine (right) after SDLME under optimal conditions. The concentrations of scopolamine in two Hair samples are shown in Table 2.These samples were spiked with scopolamine standards to assess matrix effects.

These results demonstrated that the hair sample matrices had little effect on the SDLME of scopolamine. It is clear from the above discussion that SDLME was combined with HPLC for the determination of scopolamine in Hair samples may have a good potential for extraction

Table 1. Comparison between current methods for determination of scopolamine with this work.

\begin{tabular}{|c|c|c|c|c|c|c|c|c|c|}
\hline Matrix & Method & Detection & LOD & LOQ & $\mathrm{DLR}^{1}$ & $\mathrm{RSD} \%$ & $r 2$ & Recovery $\%$ & Reference \\
\hline Blood and urine & LC-MS/APCI & MASS & $\begin{array}{c}0.7 \\
\mathrm{~g} \cdot \mathrm{mL}^{-1}\end{array}$ & $\begin{array}{c}0.9 \\
\mathrm{ng} \cdot \mathrm{ml}\end{array}$ & $0.9-25 \mathrm{ng} \cdot \mathrm{mL}^{-1}$ & $4.8-7.5$ & 0.98 & $76-100$ & 28 \\
\hline $\begin{array}{c}\text { gastrointestinal } \\
\text { drug }\end{array}$ & HPLC & UV & $\begin{array}{c}0.001 \\
\mathrm{~g} \cdot \mathrm{mL}^{-1}\end{array}$ & $\begin{array}{c}0.004 \\
\mu \mathrm{g} \cdot \mathrm{mL}^{-1}\end{array}$ & $\begin{array}{c}0.003-0.09 \\
\mu \mathrm{g} \cdot \mathrm{mL}^{-1}\end{array}$ & 2.0 & 0.9998 & 99.9 & 29 \\
\hline viscera samples & SPE-HPLC & MASS & $\begin{array}{c}100 \\
\mathrm{pg} \cdot \mathrm{mL}^{-1}\end{array}$ & $\begin{array}{c}1 \\
\mathrm{ng} \cdot \mathrm{L}^{-1}\end{array}$ & $\begin{array}{c}100-0.000 \\
\mathrm{~g} \cdot \mathrm{mL}^{-1}\end{array}$ & - & 0.9982 & - & 30 \\
\hline Plant root & SPE- HPLC & UV & $0.8 \mathrm{ng}$ & - & $8-200 \mathrm{~g} \cdot \mathrm{mL}^{-1}$ & 4.9 & - & 85.4 & 31 \\
\hline $\begin{array}{c}\text { Pharmaceuticals } \\
\text { sample }\end{array}$ & $\begin{array}{c}\text { PVC } \\
\text { membrane } \\
\text { electrod }\end{array}$ & potentiometric & $\begin{array}{l}8 \times 10^{-7} \\
\mathrm{~mol} \cdot \mathrm{dm}^{-3}\end{array}$ & - & $\begin{array}{l}10^{-2}-10^{-6} \\
\mathrm{~mol} \cdot \mathrm{dm}^{-3}\end{array}$ & 1.5 & 0.999 & 99 & 32 \\
\hline $\begin{array}{l}\text { biological } \\
\text { samples }\end{array}$ & $\begin{array}{l}\text { MIP-SPE } \\
\text {-HPLC }\end{array}$ & UV & $20 \mathrm{ng}$ & - & $\begin{array}{c}1-100 \\
\mu \mathrm{g} \cdot \mathrm{mL}^{-1}\end{array}$ & - & 0.9956 & 79 & 33 \\
\hline plant & HPLC & UV & $\begin{array}{c}0.5 \\
\mathrm{mg} \cdot \mathrm{L}^{-1}\end{array}$ & $1 \mathrm{mg} \cdot \mathrm{L}^{-1}$ & - & - & 0.9960 & - & 34 \\
\hline Hair samples & $\begin{array}{l}\text { SDLME } \\
\text {-HPLC }\end{array}$ & PAD & $\begin{array}{c}0.1 \\
\mathrm{ng} \cdot \mathrm{ml}^{-1}\end{array}$ & $10 \mathrm{ng} \cdot \mathrm{ml}^{-1}$ & $\begin{array}{c}10-10,000 \\
\mathrm{ng} \cdot \mathrm{ml}^{-1}\end{array}$ & 5.4 & 0.9978 & $89-95$ & This work \\
\hline
\end{tabular}

Dynamic Linear Range. 
Table 2. The result of scopolamine determination in the difference hair samples with relative recoveries.

\begin{tabular}{|c|c|c|c|}
\hline Sample Hair & Scopolamine Added $\left(\mathrm{ng} \cdot \mathrm{mL}^{-1}\right)$ & Scopolamine Founded(ng $\left.\cdot \mathrm{mL}^{-1}\right)$ & Recovery\% \\
\hline \multirow{3}{*}{1} & 0.00 & 0.00 & - \\
\hline & 10 & 9.4 & 94.0 \\
\hline & 100 & 96.0 & 96.0 \\
\hline \multirow{3}{*}{2} & 0.00 & 10 & - \\
\hline & 10 & 19.0 & 95.0 \\
\hline & 30 & 39.7 & 97.5 \\
\hline
\end{tabular}

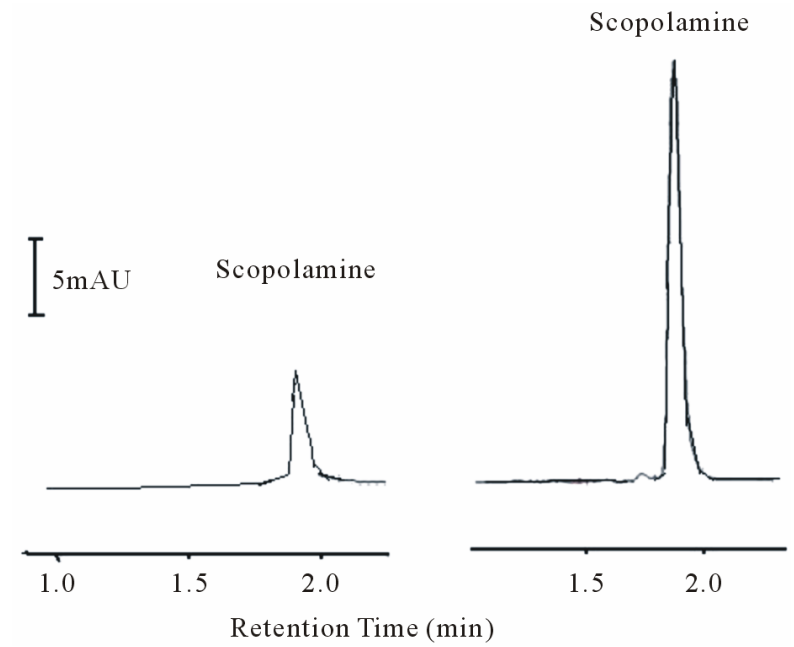

Figure 6. HPLC analysis of human hair prior (left) and after spiking with scopolamine (right) after SDLME under optimal conditions.

and determination from biological samples.

\section{Conclusions}

The aim of the present study was to develop and validate a rapid, sensitive, robust and reliable method for the quantitative determination of the drug abuse in human hair by

HPLC and the results obtained with the method described above indicate that SDLME methodology is a good alternative extraction technique for scopolamine in hair samples.

In this study we showed that SDLME coupled with HPLC was successfully applied for scopolamine analysis. Compared to the most conventional extraction procedures, this extraction technique requires a very little aqueous sample solution and very little expensive and toxic organic extractant. In our method, we introduced a reliable qualitative and quantitative technique for determination of scopolamine at low level of concentration in hair. In the mean time hair sample has some advantages over the other biological samples like urine and blood, such as long time of drug residence in the sample and low risk of side effect in transferring to examiner. On the other hand, this method is very fast, easy and simple. As be showed in other researches [34], low detection limits and high enrichment factors also are readily achieved in present work. The results of this study are applicable in biological material, drugs and forensic toxicology.

\section{Acknowledgements}

The authors would like to acknowledge the Islamic Azad University of Mashhad, Iran for financial support of this work.

\section{References}

[1] B. Dräger, "Analysis of Tropane and Related Alkaloids," Journal of Chromatography A, Vol. 978, No. 1-2, November 2002, pp. 1-35. doi:10.1016/S0021-9673(02)01387-0

[2] J. H. B. Atropine, "Scopolamine and Related Antimuscarinic Drugs," In: A. Gilman, T. W. Rall, A. S. Nies, P. Taylor, Eds, Goodman and Gilman's the Pharmacological Basis of Therapeutics, 8th Edition, Pergamon, New York, 1990, pp. 150-165.

[3] L. Eleore, J. C. López-Ramos, P. J. Yi and J. M. DelgadoGarcía, "The Cognitive Enhancer T-588 Partially Compensates the Motor Associative Learning Impairments Induced by Scopolamine Injection in Mice," Behavioral Neuroscience, Vol. 121, No. 6, December 2007, pp. 1203-1214.

[4] P. Kintz, M. Villain, J. Evans, M. L. Pujol, G. Salquebre and V. Cirimele, "A Case of Abuse in Which Children were Forced to Take Tablets Containing Scopolamine: Segmental Analysis of Hair for Scopolamine by Ultra Performance Liquid Chromatography Mass Spectrometry," Forensic Toxicology, Vol. 25, No. 1, 2007, pp. 4952. doi:10.1007/s11419-007-0026-6

[5] P. Kintz and P. Mangin, "What Constitutes a Positive Result in Hair Analysis: Proposal for the Establishment of Cut-off Values," Forensic Science International, Vol. 70, No. 1, January 1995, pp. 3-11. doi:10.1016/0379-0738(94)01621-B 
[6] H. Sachs, "Theoretical Limits of the Evaluation of Drug Concentrations in Hair Due to Irregular Hair Growth," Forensic Science International, Vol. 70, No. 1, January 1995, pp. 53-61. doi:10.1016/0379-0738(94)01611-8

[7] Y. Nakahara and R. Kikura, "Hair Analysis for Drugs of Abuse XIX Determination of Ephedrine and Its Homologs in Rat Hair and Human Hair," Journal of Chromatography B, Vol. 700, No. 1-2, October1997, pp. 83-91.

doi:10.1016/S0378-4347(97)00332-0

[8] H. G. Ugland, M. Krog and K. E. Rasmussen, "Liquid-Phase Microextraction as a Sample Preparation Technique Prior to Capillary Gas Chromatographic-Determination of Benzodiazepines in Biological Matrices," Journal of Chromatography B, Vol. 749, No. 1, November 2000, pp. 85-92. doi:10.1016/S0378-4347(00)00382-0

[9] P. Kintz, M. Villain, Y. Barguil, J. Y. Charlot and V. Cirimele, "Testing for Atropine and Scopolamine in Hair by LC-MS-MS after Datura Inoxia Abuse," Journal of Analytical Toxicology (JAT), Vol. 30, No. 7, September 2006, pp. 454-457.

[10] M. Ma and F. F. Cantwell, "Solvent Microextraction with Simultaneous Back-Extraction for Sample Cleanup and Preconcentration into a Single Microdrop," Analytical Chemistry, Vol. 71, No. 2, December 1999, pp. 388-393.

[11] M. Ma and F. F. Cantwell, "Solvent Microextraction with Simultaneous Back-Extraction for Sample Cleanup and Preconcentration," Quantitative Extraction Analytical Chemistry, Vol. 70, No. 18, August 1998, pp. 3912-3919. doi:10.1021/ac980174n

[12] L. Yangcheng, L. Quan, L. Guangsheng and D. Youyuan, "Directly Suspended Droplet Microextraction," Analytica Chimica Acta, Vol. 566, No. 2, May 2006, pp. 259-264. doi:10.1016/j.aca.2006.02.072

[13] P. Kintz,V. Cirimele, F. Vayssette and P. Mangin, "Hair Analysis for Nordiazepam and Oxazepam by Gas Chromatography-Negative-Ion Chemical Ionization Mass Spectrometry," Journal of Chromatography B, Vol. 677, No. 2 March 1996, 241-244. doi:10.1016/0378-4347(95)00444-0

[14] L. Zhao, L. Zhu, H. K. Lee, "Analysis of Aromatic Amines in Water Samples by Liquid-Liquid-Liquid Microextraction with Hollow Fibers and High-Performance liquid Chromatography," Journal of Chromatography A, Vol. 963, No. 1-2, July 2002, pp. 239-248. doi:10.1016/S0021-9673(02)00544-7

[15] L. Hou and H. K. Lee, "Dynamic Three-Phase Microextraction as a Sample Preparation Technique Prior to Capillary Electrophoresis," Analytical Chemistry, Vol. 75, No. 11, April 2003, pp. 2784-2789.

[16] A. Sarafraz-Yazdi and Z. Es'haghi, “Two-Step Hollow Fiber-Based, Liquid-Phase Microextraction Combined with High-Performance Liquid Chromatography: A New Approach to Determination of Aromatic Amines in Water," Journal of Chromatography A, Vol. 1082, No. 2, May 2005, pp. 136-142. doi:10.1002/1615-9314(20010801)24:7<495::AID-JSSC4 95>3.0.CO;2-B
[17] JÅ. Jönsson and L. Mathiasson, "Memrane Extraction in Analytical Chemistry," Journal of Seperation Science, Vol. 24, No. 7, August 2001, pp. 495-507.

[18] A. Sarafraz Yazdia, F. Mofazzeli and Z. Es'haghi, "Determination of 3-Nitroaniline in Water Samples by directly Suspended Droplet Three-Phase Liquid-Phase Microextraction Using 18-Crown-6 Ether and HighPerformance Liquid Chromatography," Journal of Chromatography A, Vol. 1216, May 2009, pp. 5086- 5091.

[19] E. Psillakis and N .Kalogerakis, "Developments in Liquid-Phase Microextraction," Trends in Analytical Chemistry, Vol. 22, No. 9, October 2003, pp. 565-574.

[20] S. Palmarsdottir, E. Throdarson, L. E. Edholm and J. A. Jönsson, "Miniaturized Supported Liquid Membrane Device for Selective On-Line Enrichment of Basic Drugs in Plasma Combined with Capillary Zone Electrophoresis," Analytical Chemistry, Vol. 69, No. 9, May1997, pp. 1732-1737. doi:10.1021/ac960668p

[21] M. R. Hoffmann, I. Hua and R. Höchemer, “Application of Ultrasonic Irradiation for the Degradation of Chemical Contaminants in Water," Ultrasonics Sonochemistry, Vol. 3, No. 3, November 1996, pp. S163-172.

[22] E. Psillakis and N. Kalogerakis, "Solid-Phase Microextraction Versus Single-Drop Microextraction for the Analysis of Nitroaromatic Explosives in Water Samples," Journal of Chromatography A, Vol. 938, No.1-2, 2001, pp. 113-120. doi:10.1016/S0021-9673(01)01417-0

[23] G. Shen and H. K. Lee, "Hollow Fiber-Protected Liquid-Phase Microextraction of Triazine Herbicides," Analytical Chemistry, Vol. 74, No. 3, February 2002, pp. 648-654.

[24] K. E. Rasmussen, S. Pedersen-Bjergaard, M. Krogh, H. G. Ugland and T Gronhaug, "Development of a Simple Invial Liquid-Phase Microextraction Device for Drug Analysis Compatible with Capillary Gas Chromatography, Capillary Electrophoresis and High-Performance Liquid Chromatography," Journal of Chromatography A, Vol. 873, No. 1, March 2000, pp. 3-11. doi:10.1016/S0021-9673(99)01163-2

[25] Z. Es'haghi, "Determination of widely Used Non-Steroidal Anti-Inflammatory Drugs in Water Samples by in Situ Derivatization, Continuous Hollow Fiber LiquidPhase Microextraction and Gas Chromatography-Flame Ionization Detector," Analytica Chimica Acta, Vol. 641, No. 1-2, May 2009, pp. 83-88. doi:10.1016/j.aca.2009.03.043

[26] S. De. Koning, M. Kurano, H. G .Janssen and U. A. T. Brinkman, "AT-Column, a Novel Concentrating Technique for Large-Volume Injections in Gas Chromatography," Journal of Chromatography A, Vol. 1023, No. 2, January 2004, pp. 165-174. doi:10.1016/j.chroma.2003.10.031

[27] A. Skulska, M. Kała, P. Adamowicz , E. Chudzikiewicz, W. Lechowicz, P. Lek, "Determination of Fentanyl, Atropine and Scopolamine in Biological Material Using LC-MS/APCI Methods," Przeglad lekarski, Vol. 64, No. 4-5, 2007, pp. 263-267.

[28] M .Nakamura, M. Ono, T. Nakajima, Y. Ito, T. Aketo and 
J. Haginaka, "Uniformly Sized Molecularly Imprinted Polymer for Atropine and Its Application to the Determination of Atropine and Scopolamine in Pharmaceutical Preparations Containing Scopolia Extract," Journal of Pharmaceutical and Biomedical Analysis, Vol. 37, No. 2, February 2005, pp. 231-237. doi:10.1016/j.jpba.2004.10.017

[29] P. A. Steenkamp, N. M. Harding, F. R. van Heerden and B. E. Van Wyk, "Fatal Datura Poisoning: Identification of Atropine and Scopolamine by High Performance Liquid Chromatography/Photodiode Array/Mass Spectrometry," Forensic Science International, Vol. 145, No. 1, October 2004, pp. 31-39.

[30] L. Kursinszki, H. Hank, I. László and É. Szőke, “Simultaneous Analysis of Hyoscyamine, Scopolamine, 63-hydroxy-hyoscyamine and Apoatropine in Solanaceous Hairy Roots by Reversed-Phase High-Performance Liquid Chromatography," Journal of Chromatography A, Vol. 1091, No. 1-2, October 2005, pp. 32-35. doi:10.1016/j.chroma.2005.07.016

[31] G. A. H. Mostafa, "Potentiometric PVC Membrane Sen- sor for the Determination of Scopolamine in Some Pharmaceutical Formulations," Analytical Science, Vol. 18, No. 12, September 2002, pp. 1335-1338. doi:10.2116/analsci.18.1335

[32] G. Theodoridis, A. Kantifes, P. Manesiotis, N. Raikos, H. Tsoukali-Papadopoulou, "Preparation of a Molecularly Imprinted Polymer for the Solid-Phase Extraction of Scopolamine with Hyoscyamine as a Dummy Template Molecule," Journal of Chromatography A, Vol. 987, No. 1-2, February 2003, pp. 103-109. doi:10.1016/S0021-9673(02)02048-4

[33] A. S. Bahmanzadegana and F. Sonboli, "Determina- tion of Hyoscyamine and Scopolamine in Four Hyoscyamus Species from Iran A," Iranian Journal of Pharmaceutical Research, Vol. 8, No. 1, 2009, pp. 65-70.

[34] A. Sarafraz Yazdi and Z. Es'haghi, "Liquid-Liquid-Liquid Phase Microextraction of Aromatic Amines in Water Using Crown Ethers by High-Performance Liquid Chromatography with Monolithic Column," Talanta, Vol. 66, No. 3 , January 2005, pp. 664-669. doi:10.1016/j.talanta.2004.12.026 